\title{
Vending Machines in Australian Hospitals: Are They Meeting the Needs of the Consumer?
}

\author{
Jennifer Utter, PhD, RD; Sally McCray, BSc, GradDip, Nut \& Diet, APD
}

\begin{abstract}
The current report explores how well vending machines are meeting the needs of health care organizations and their staff and visitors in Australia. Hospital vending machines often provide the only source of food through the night to staff and visitors and traditionally offer less-healthy options. Findings presented in this report suggest that vending machines are not meeting current statewide policies and guidelines for healthier food environments in health care. This is despite widespread support for healthier refreshments in hospitals by staff, visitors, and patients. Alternatives to traditional vending and opportunities for nutrition educators and researchers are discussed.
\end{abstract}

Key Words: hospital, vending machine, policy, nutrition (J Nutr Educ Behav. 2021;53:183-186.)

Accepted November 22, 2020.

\section{INTRODUCTION}

Health care administrators face a significant challenge to providing affordable meal and snack options to their staff who work through the nights and weekends and to visitors who may face long and unexpected waits. As such, vending machines are often used to meet this need as they are compact, cost-efficient, and require no staffing. However, traditional vending machines are limited in the types of foods and drinks they offer, commonly dispensing snack foods high in salt, sugar, and fat and sugar-sweetened beverages. ${ }^{1}$ While innovations in vending mean that healthier vending options are now available (eg, fresh fruit, healthy salads), they are not yet widespread through the health care sector in Australia. This limitation presents challenges to meeting the needs of after-hours staff who may need to rely on purchased meals and snacks during their shifts and to meeting obligations for creating healthy work environments. It also conflicts with public perceptions that health care organizations are healthy places and undermines the health and wellbeing of their own workforce.

For health care staff especially, improving eating behaviors is essential given the concerns about their health, well-being, and nutrition. ${ }^{2,3}$ Hospital workers experience high rates of noncommunicable diseases, including obesity and cardiovascular risk factors. ${ }^{3}$ In addition, people working in shifts, like many hospital staff, also experience poorer indicators of health, well-being, and poorer nutrition than employees who work standard hours. ${ }^{4-6}$ The health and wellness of hospital staff ultimately affects the health and productivity of the workforce.

Increasingly, governments and health care organizations are recognizing their responsibility to create healthy worksites for people working in health care, and existing evidence

Department of Dietetics and Foodservices, Mater Health, South Brisbane, Queensland, Australia

Conflict of Interest Disclosure: The first author of this article (J. Utter) serves on the JNEB staff as Associate Editor. Review of this article was handled, exclusively, by the Editor-in-Chief to minimize conflict of interest. The rest of the authors have not stated any conflicts of interest.

Address for correspondence: Jennifer Utter, PhD, RD, Department of Dietetics and Foodservices, Mater Health, Raymond Terrace, South Brisbane, Queensland 4101, Australia;

E-mail: jennifer.utter@mater.org.au

(C) 2020 Society for Nutrition Education and Behavior. Published by Elsevier Inc. All rights reserved.

https://doi.org/10.1016/j.jneb.2020.11.013

suggests that healthier vending options improve dietary choices. ${ }^{8-10}$ As such, many Australian states have developed strategies to improve the nutrition environment for staff and visitors in health care settings. ${ }^{11,12}$ These policy guidelines vary by state but generally encourage healthier options while limiting unhealthy options.

This article aimed to explore how well vending machines are meeting the needs of health care organizations and their staff and visitors in Australia. The current report is a narrative review of all published research on vending machines in health care settings in Australia, up to May 2020. The review explores 2 main concepts: how well vending contributes to a healthier food environment in hospitals and consumer views and satisfaction of current vending offerings.

\section{HEALTHY OFFERINGS IN HOSPITAL VENDING MACHINES}

At the time of this writing, statewide food and nutrition strategies for health care settings were common across Australia. ${ }^{11,12}$ These initiatives broadly aim to improve the quality of foods and drinks provided and promoted on-site, including vending machines. The details of these policy guidelines vary, namely in the classification systems used to categorize healthy and unhealthy foods and in the thresholds of unhealthy foods 
Table. Description of Policy Guidelines in Australian States and Evidence of Compliance

\section{State}

Western Australia

New South Wales

Healthy Options WA: Food and Nutrition Policy for WA Health Services and Facilities, $2018^{\mathrm{a}}$

\section{The Framework, 2017
(replaces Live Life Well @ Health, 2007)}

\section{New South Wales Live Life Well @ Health, \\ Live Life Well @ Health,
$2007^{a}$}

\begin{tabular}{|c|c|}
\hline Victoria & $\begin{array}{l}\text { Healthy Choices: Food and } \\
\text { drink guidelines for Victo- } \\
\text { rian public hospitals, } \\
2010\end{array}$ \\
\hline
\end{tabular}

South Australia

Queensland itors in SA Health Facilities policy, $2010^{a}$

A Better Choice Healthy

\section{Healthy Vending} Requirements

At least $50 \%$ of all food and drink on offer and display must be green (healthier options), with no more than $20 \%$ classified as red (unhealthy options)

At least $75 \%$ of foods and drinks must be classified as every day (healthier) options, with no sugarsweetened beverages

At least $80 \%$ of foods and drinks should be healthier (green or amber), and red drinks be less than $375 \mathrm{~mL}$
At least $50 \%$ of all food and drink on offer and display must be green (healthier options), with no more than $20 \%$ classified as red

\section{A maximum of $20 \%$ of foods and drinks displayed are red (unhealthy) options}

Red (unhealthy) foods and drinks removed completely from vending machines

\section{Audit Results}

2018-2019, statewide audit ${ }^{15}$ $60 \%$ of vending machines compliant across state

2017 (baseline), an audit of 2 public hospitals in New South Wales ${ }^{18}$ $23 \%$ of vending machines met the target for drinks

Zero machines met the target for food

Audits at baseline and follow-up,

Hunter New England Local Health District $^{13}$

2007: no machines (drinks or food) compliant

2011: 26\% drink machines and 6\% food machines compliant

2007: 29\% drinks and 1\% food green/ amber

2011: 51\% drinks and 3\% food green/ amber

2012-2013, changes in vending sales in 1 metropolitan health service ${ }^{14}$ March 12 foods sold: 0 green and $80 \%$ red

April 13 foods sold: $5 \%$ green and $60 \%$ red (calculated)

March 12 drinks sold: $17 \%$ green and $62 \%$ red

April 13 drinks sold: $32 \%$ green and $43 \%$ red (calculated)

2012 , statewide survey ${ }^{17}$

$40 \%$ of vending machines compliant Food and Drink Supply Strategy for Queensland Health Facilities, $2007^{a}$
2009 , statewide survey ${ }^{16}$

$74 \%$ of site managers reported complete removal of red items from vending

WA indicates Western Australia.

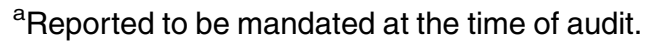

permitted. To achieve compliance, these strategies require additional time and resources for health care services for implementation, auditing, and reporting.

Despite the high-level guidance of these strategies, their effectiveness in improving the nutrition environment of hospital vending machines appears low. Several audits across multiple states have been conducted over the past 10 years. ${ }^{13-18}$ Findings from these audits suggest that, even after implementation of the policy guidelines, vending machines remain poorly compliant (Table). The most recent statewide audit of the policy in Western Australia found that after a 6 month lead-in period, only $60 \%$ of vending machines met all of the policy requirements. ${ }^{15}$ Another published statewide evaluation was in Queensland,
Australia, in 2009. While findings suggested that $74 \%$ of vending machines had completely removed all unhealthy drinks, success with snacks was less notable. ${ }^{16}$ It is also likely that the modest response rate $(<50 \%)$ of facilities reporting may have positively skewed the findings. After policy implementation in health care services in the regions of New South Wales ${ }^{13,18}$ and Victoria, ${ }^{14}$ nutritional quality of 
foods and drinks available and sold through vending machines had improved, though overall were not fully compliant with requirements.

Collectively, these findings suggest that government-initiated policies and directives alone may be insufficient for improving healthy food and drink options in vending machines.

\section{VENDING MACHINES AND CONSUMER PREFERENCES AND EXPECTATIONS}

Despite their generally unhealthy offerings, there is a strong appetite for healthier food and drinks in vending machines from those who use them. One study reported that almost all (90\%) parents with children in an Australian hospital believed that retail outlets in hospitals should provide mostly healthy items. ${ }^{13}$ Residents of a long-stay rehabilitation facility reported valuing their health highly and recognized that sugarsweetened beverages posed a threat to their health. ${ }^{19}$ In a survey of hospital staff, visitors, and patients, more than $80 \%$ felt the vending machine options were too unhealthy and identified nuts, muesli bars, and dried fruit as preferences for healthier options. ${ }^{20}$ Last, in an interview with a senior executive of a hospital, they noted that vending machines contributed negligibly to the overall hospital budget and, in their experience, removing sugary drinks and chocolates did not cause any financial hardship. ${ }^{14}$

\section{DISCUSSION}

Vending machines remain commonplace in hospitals and health care organizations, despite not appearing to meet the needs of staff, visitors, or hospitals themselves. Consumers view vending offerings as unhealthy and independent audits of what is available to confirm those perceptions. Vending machines, particularly those with snacks, remain noncompliant with government strategies. Yet, as an industry, vending sales in Australia continue to grow, with 1 company holding nearly half of the market share. ${ }^{21}$
Hospital vending machines may be difficult to change, even under government direction. This barrier suggests that for policy implementation to be effective, strategies that are time and resource-intensive are needed. The findings of audits reviewed in the current report did not extensively describe the operationalization of the policies and guidelines. That said, a body of work suggests that successful implementation requires executive support, explicit contracts, dietetic input, and a suitable supply from vendors. $^{22,23}$ Specifically, an evaluation of healthy vending policies effectively implemented in 4 cities in the US highlighted the necessary role that high-level leadership and multidisciplinary working groups (with expertise in nutrition, legal matters, contracts, and healthy vending) played in the success of each city. ${ }^{24}$ This team-based approach required good relationships which took time to develop. Clear communication about expectations and violations (daily fines for noncompliance or machine removal) were critical. Ongoing monitoring and compliance required person-power and time.

The noncompliance of hospital vending machines with government policy reported here may, in part, be explained by a number of factors other than the lack of implementation. First, it is possible that there have been inadequate resources available for evaluation and auditing. As such, timely and accurate data on compliance is not available. Second, another explanation may be that compliance data is not published in public forums and, therefore, inaccessible. Finally, it is also conceivable that there has been insufficient time for health care organizations to implement the strategies because they were enacted. Organizations may be bound to existing vending contracts, which present substantial challenges for policy implementation.

Improving the nutritional quality of foods and drinks available in vending machines in the current climate is likely to present numerous challenges. Perhaps it is time to reconsider the value of conventional vending machines to health care organizations and consider alternatives for feeding staff and visitors who are on-site after-hours. One option is for health care organizations to diversify their vending contracts to support smaller providers who specialize in healthier vending. Innovations have been made whereby vending machines can offer fresh fruits, salads, and healthy meals. Other alternatives require a shift away from vending machines to other retail options, such as micromarkets (small, automated stores), that allow for a wider range of healthier options.

\section{IMPLICATIONS FOR RESEARCH AND PRACTICE}

It is time to think more critically about the role of vending machines in health care settings and how to best nourish the staff and visitors who are on-site after-hours. For those working in the health care setting, executive support for creating healthier worksites, developing supporting nutrition education and staff well-being initiatives, and routine auditing of the nutrition environment are essential to creating healthier food environments. Alternatives to traditional vending (such as healthier vending and micromarkets) may offer new solutions to feeding staff and visitors quickly and healthily. Government policy guidelines provide a useful platform and tool for benchmarking these issues. Statewide government policy guidelines, though, would be strengthened through more consistencies across states. These policies would send a clear message to vendors about what is expected and acceptable in healthier vending. Research also plays an important role in conducting independent and robust evaluations of the hospital food environment and its impact on the health and well-being of staff and the wider community.

\section{REFERENCES}

1. Grech A, Hebden L, Roy R, AllmanFarinelli M. Are products sold in university vending machines nutritionally poor? A food environment audit. Nutr Diet. 2017;74:185-190.

2. Jackson CL, Wee CC, Hurtado DA, Kawachi I. Obesity trends by industry 
of employment in the United States, 2004 to 2011. BMC Obes. 2016;3:20.

3. Sharma SV, Upadhyaya M, Karhade M, et al. Are hospital workers healthy?: a study of cardiometabolic, behavioral, and psychosocial factors associated with obesity among hospital workers. J Occup Environ Med. 2016;58:1231-1238.

4. Amani R, Shiftworking Gill T. nutrition and obesity: implications for workforce health- a systematic review. Asia Pac J Clin Nutr. 2013;22:505-515.

5. Pepłońska B, Nowak P, Trafalska E. The association between night shift work and nutrition patterns among nurses: a literature review. Med $P r$. 2019;70:363-376.

6. Smith P, Fritschi L, Reid A, Mustard C. The relationship between shift work and body mass index among Canadian nurses. Appl Nurs Res. 2013;26:24-31.

7. Australian Institute of Health and Welfare. Risk Factors and Participation in Work. Canberra, Australia: Australian Institute of Health and Welfare; 2010.

8. Bos C, van der Lans IA, van Kleef E, van Trijp HCM. Promoting healthy choices from vending machines: effectiveness and consumer evaluations of four types of interventions. Food Policy. 2018;79:247-255.

9. Lane C, Naylor PJ, Tomlin D, et al. Healthy vending contracts: do localized policy approaches improve the nutrition environment in publicly funded recreation and sport facilities. Prev Med Rep. 2019;16:100967.

10. Viana J, Leonard SA, Kitay B, Ansel D, Angelis P, Slusser W. Healthier vending machines in a university setting: effec- tive and financially sustainable. Appetite. 2018;121:263-267.

11. Queensland Health. Healthier Food and Drinks at Healthcare Facilities. Brisbane, Australia: Queensland Health; 2019.

12. Victoria State Government, Department of Health and Human Services. Healthy Choices: Policy Guidelines for Hospitals and Health Services. Melbourne, Australia: Victoria State Government, Department of Health and Human Services; 2016.

13. Bell C, Pond N, Davies L, Francis JL, Campbell E, Wiggers J. Healthier choices in an Australian health service: a pre-post audit of an intervention to improve the nutritional value of foods and drinks in vending machines and food outlets. BMC Health Serv Res. 2013;13:492.

14. Boelsen-Robinson T, Backholer K, Corben K, Blake MR, Palermo C, Peeters $\mathrm{A}$. The effect of a change to healthy vending in a major Australian health service on sales of healthy and unhealthy food and beverages. Appetite. 2017;114:73-81.

15. Government of Western Australia. Department of Health. 2018-19 statewide audit of policy implementation. Perth, Australia: Government of Western Australia, Department of Health; 2020.

16. Miller J, Lee A, Obersky N, Edwards R. Implementation of A Better Choice Healthy Food and Drink Supply Strategy for staff and visitors in government-owned health facilities in Queensland, Australia. Public Health Nutr. 2015;18:1602-1609.
17. Health SA. Healthy Food and Drink Choices for Staff and Visitors in SA Health Facilities Policy: Evaluation. Adelaide, South Australia: SA Health; 2012.

18. Tsai C, Svensen E, Flood VM, et al. Healthiness of food and beverages for sale at two public hospitals in New South Wales, Australia. Nutrients. 2018;10:216.

19. Henning Cruickshank A, McCambridge L, Juffs P, Walker JL. Consumer experiences of a healthier drinks initiative at a secure residential rehabilitation facility - a cross-sectional study. Australas Psychiatry. 2020;28:322-327.

20. Carrad AM, Louie JCY, Milosavljevic M, Kelly B, Flood VM. Consumer support for healthy food and drink vending machines in public places. Aust N ZJ Public Health. 2015;39:355-357.

21. Euromonitor International. Vending in Australia. https://www.euromonitor. com/vending-in-australia/report. Accessed May 5, 2020.

22. Jilcott Pitts SB, Graham J, Mojica A, et al. Implementing healthier foodservice guidelines in hospital and federal worksite cafeterias: barriers, facilitators and keys to success. J Hum Nutr Diet. 2016;29:677-686.

23. Kolasa KM. Creating and sustaining a healthy food environment in hospitals contracting with a food service management company. Nutr Today. 2018;53:5-12.

24. Glanz K, Bromberg J, Mirafzali Y, Green S. Evaluating Healthy Vending Policies for Youth in Four Cities. Philadelphia, PA: University of Pennsylvania; 2018. 